\title{
Estudo geomorfológico como subsídio a análise do espaço urbano de Petrópolis - R.J.
}

\author{
Luiz F. H. Gonçalves \\ Andréa C. C. Santos \\ UFRJ - Universidade Federal do Rio de Janeiro \\ Departamento de Geografia - Laboratório de Geomorfologia Experimental e Erosão dos Solos \\ 21.940-590 - Rio de Janeiro - R.J. \\ lagesolo@ufrj.igeo.br
}

\begin{abstract}
This paper aims the making of a geomorphological map, which serve as a subside for anlysis on enviromental quality in the city of Petróplis - R.J.. This map will be associated to other subject maps, which together with the ways of occupation, will demonstrate the antropic that will occur in this area, through enviromental units.
\end{abstract}

Keywords: enviromental units, urban areas, geomorphological map

\section{Introdução}

O municipio de Petrópolis. localiza-se na região Serrana do Estado do Rio de Janeiro, na Serra da Estrela (subsistema da Serra do Mar). sendo uma das poucas cidades que ainda conservam $e$ integram-se a parques nacionais $e$ reservas biológicas, como o Parque Nacional da Serra dos Órgãos e a Reserva Biológica de Araras, além de possuir dentro de seu sítio urbano, áreas de floresta tropical tombadas pela União, a APA de Petrópolis.

Um dos maiores desafios que o município de Petrópolis está enfrentando na atualidade, diz respeito a aplicação de uma política de uso e ocupação racional do solo urbano e preservação do meio ambiente, desafio este que se torna cada vez mais complexo, em função do crescimento urbano acelerado, da concentração populacional em áreas de risco e dos desmatamentos.

Assim, cria-se condições para ocorrerem movimentos de massa e deslizamentos, que invariavelmente, atingem a população de baixa renda estabelecida nas encostas do município, que potencialmente tornaram-se áreas de risco, sem que o poder público promova medidas para a resolução da questão habitacional, e medidas preventivas com relação ao desmatamento e suas consequências para o município.

Apesar da presença de muitas unidades de preservação no municipio, as leis de uso e ocupação do solo urbano precisam ser revistas, observando-se a preservação efetiva das áreas florestais que continuamente estão sendo ocupadas. pois o crescimento urbano, de modo geral, vem acompanhado de impactos.

O objetivo deste trabalho é reunir dados geomorfológicos, associando-os a geologia. aos índices pluviométricos, a hidrografia, a cobertura vegetal, aos diversos tipos de ocupação, e as áreas que sofreram movimentos de massa já mapeados, afim de identificar as variáveis - controle do processo de degradação que, venham subsidiar ao estudo dos impactos causados pelo processo de urbanização. Como resultado obtivemos um mapa de qualidade ambiental.

\section{Caracterização da área de estudo}

A área de estudo situa-se no município de Petrópolis $\left(1^{\circ}\right.$ distrito) ao norte do municipio do Rio de Janeiro numa altitude média de $845 \mathrm{~m}$. Estabelecido na Serra do Mar, que localmente recebe as denominações de Serra dos Órgãos e Serra da Estrela, caracteriza-se por um relevo movimentado com a presença de fraturas e falhas, desempenhando um notável controle na organização da rede de drenagem e no modelo de relevo. A área também se caracteriza pela elevada pluviosidade, principalmente no alto das escarpas que compõem a Serra do Mar, e por uma elevada concentração populacional.

$O$ processo de ocupação do espaço no município sempre exigiu que fossem consideradas muitas variáveis como: índices pluviométricos, a rede de drenagem, a geologia, dentre outros. 
Porém, a interferência antrópica tem ocorrido na área urbana sem critérios, causando inúmeros movimentos de massa e deslizamentos nas encostas, que nos últimos 50 anos vem sendo ocupadas continuamente.

\section{Metodologia}

A metodologia empregada envolveu a aplicação de técnicas de mapeamento geomorfológico, para a elaboração do mapa de compartimentação geomorfológica, permitindo associá-lo aos mapas geológico, de movimentos de massa, hidrográfico, de áreas de inundação e uso do solo da área urbana do município de Petrópolis Ainda sendo possivel associar a partir do mapa de solo, os tipos de ocupação/habitação.

O mapa de compartimentação foi confeccionado tendo como base a carta topográfica em escala 1:5000, de onde hierarquizada a rede de drenagem, foi realizado o cálculo dos desnivelamentos altimétricos, que são obtidos a partir da diferença dos valores mais elevados das curvas de nível e o mais baixos efetuado em bacias de drenagem de até segunda ordem, definindo o índice de dissecação do relevo de acordo com Meis et al (1982), onde propõem o cálculo do desnivelamento altimétrico, reconhecendo bacias de drenagem com o mesmo índice de dissecação, separando as bacias com valores diferentes através da delimitação de interflúvios $\mathrm{e}$ divisores, caracterizando no resultado final compartimentos respectivos as classes distintas de desnivelamento.

No mapa geológico foram pontuados os movimentos de massa ocorridos na área urbana no período de 1980 a 1989.

Essas informações foram associadas a um mapa de compartimentação, assim como o mapa hidrológico, o qual demosntrou que a disposição da rede de drenagem está com um grande controle estrutural, e apresenta em algumas regiões mais baixas, áreas que sofrem inundações.

A partir de todos esses componentes geomorfológicos houve um cruzamento das informações, e associamos, em última instância os resultados de mapa de uso do solo, o qual demosntra as formas de ocupação da área.

\section{Análise e discussão}

É realmente importante compreender o meio ambiente como um todo, mesmo que analisado em partes. A análise sistêmica da paisagem conduz ao estudo das relações de interdependência existentes entre os componentes do meio fisico, permitindo conhecer seus mecanismos de funcionamento, assim como a compartimentação da paisagem fisica permite a identificação de áreas homogêneas.

$E$ fundamentalmente isto que buscamos com este trabalho. A partir das classes estabelecidas por meio do mapeamento geomorfológico, podemos observar áreas homogêneas que nos serviu de base para verificar as relações de interdependência existente nas áreas, e como um destes componentes, podemos citar os movimentos de massa.

Este componente se apresenta de forma peculiar na área urbana e quando associado mais frequentemente as formas de ocupação, caracteriza chamadas unidades de risco.

Esta unidade apresenta um grande número de movimentos de massa. e forma de ocupação como loteamentos irregulares, que acabam por desmatar as encostas e cortes no relevo em áreas de alta declividade, promovendo situações de risco. Sem contar com o nível de dissecação que se apresenta em altos indices demonstrando que o substrato vem sendo trabalhado pela hidrografia de forma intensa.

As unidades de preservação se caracterizam por estarem em áreas de maior indice de dissecação com mais de $\mathbf{4 0 0}$ metros de desnivel, onde se conserva ainda a vegetação natural e consequentemente, os deslizamentos não ocorrem. pois são áreas que estão em altitudes elevadas e fortes declividades, onde a ocupação não se desenvolveu preservando-se ainda a cobertura vegetal.

As unidades consideradas estáveis se apresentam de forma peculiar com um tipo de ocupação densa, mas no entanto, os movimentos de massa não são expressivos, e os índices de dissecação são baixos, pois se caracterizam por fundos de vales e planícies aluviais. Historicamente estas foram as primeiras áreas a serem ocupadas, e o controle estrutural é forte no sentido de controlar a drenagem, que já foi retrabalhada e o problema atual está no assoreamento dos rios causando enchentes.

As unidades instáveis apresentam um nível de dissecação de média a alta. e com um nivel de ocupação crescente. Estas áreas estão em processo de retrabalhamento do relevo. e os movimentos de massa apresentam-se de forma crescente. Observa-se que ocupação humana se deu em setores de encosta menos declivosos. embora já se verifique a ocupação em terrenos extremamente perigosos, como as faixas de sopé de encostas ingremes e rochosas. 
Com todas essas unidades, chegamos a um mapa final no qual demonstra a qualidade ambiental.

\section{Conclusão}

Este mapa vem então apresentar a influência antrópica no meio ambiente, face a sua capacidade natural de suporte onde levanta questões de natureza sócio-econômica e ainda, análise das relações meio físico-uso, estabelecendo uma avaliação dessas relações. É importante ressaltar as relações feitas com os componentes do meio fisico, que só contribuem para uma melhor visualização entre eles, que associada a questão sócio-econômica. em relação as áreas urbanas, vem demostrar de forma clara os impactos causados pela interferência antrópica

\section{Referências bibliográficas}

GONÇALVES, L.F.H. \& SANTOS, A.C.C. (1996)

A concentração populacional e os processos antrópicos atuantes no $1^{\circ}$ e parte do $2^{\circ}$ distrito de Petrópolis - R.J. In: Encontro Nacional de Geógrafos, 10, Recife, 1996. Anais. UFPE Recife - PE. 2: 224 - 225.

GONÇALVES, L.F.H. \& GUERRA, A. J. T. (1995). A concentração populacional e seus impactos ambientais no município de Petrópolis - R.J. In: Simpósio Nacional de Geografia Física Aplicada, 6, Goiânia, 1995. Anais. UFG Goiânia - GO. 2: 36 - 41.

MEIS, M.R: MIRANDA L.H.G. \& FERNANDES, N. F. (1982). Desnivelamento de altitude como parâmetro para a compartimentação do relevo: Bacia do médio baixo Paraiba do Sul. In: Congresso Brasileiro de Geologia, 32, Salvador, 1982. Anais. SBG Salvador, BA. 4: 1489 - 1509.

SILVA. T. M.; MELLO, C. L. \& MOURA J. R. S. (1983). Compartimentação morfoestrutural da região do médio vale do Rio Paraíba do Sul e áreas serranas adjacentes. In: Simpósio de Geologia do Sudeste, 3, Rio de Janeiro. 1993. Anais. UERJ Rio de Janeiro, R.J. 1: 103 - 107.

SILVA T. M. \& MOURA. J. R. S. (1995). Degradação Ambiental no médio vale do Paraíba do Sul Fluminense: uma avaliação de condicionamentos geomorfológicos. geológicos e hidrológicos. In: Simpósio Nacional de Geografia Física Aplicada; 6 , Goiânia, 1995. Anais. UFG Goiânia, GO. 1: $262-267$. 